\section{Mind control}

SIR - The mania for research publication that is sweeping the world, POPS (publish or perish syndrome), is an example of a disease caused by a "mind virus" 1 . The vector is the scientific journal, which carries the virus in the form of communications world-wide to susceptible victims. Fear of the wrath of the employing authority, together with the promise of financial reward or better job prospects for published articles, potentiates the 'virus' and causes the number of articles and journals to proliferate, in turn infecting a new population of susceptible hosts. The external source of energy required for the propagation of the infection is the research grant.

The infectivity of the virus is not very high, as there are various 'immune' control mechanisms. One of these is the journal referee but, judging from recent reports, this mechanism is not very effective $^{2,3}$. Those 'viruses' which escape this mechanism and end up being published still do not have a high infectivity rate, as a large percentage are never again quoted ${ }^{4}$. A second control mechanism is the inherent resistance to research work in many individuals. This is often broken down by pressure from the employing organization, but a considerable number of individuals have over the years built up a strong immunity to this pressure and successfully escape infection.

Factors enhancing resistance to the 'research virus' are of great value as the vectors are already saturated; even the multiplication of these vectors in recent years cannot cope with the virus load. I think a very good case could be made for more vigorous control of the 'research virus'. Perhaps we should start by limiting the external source of energy, or possibly the vectors.

\section{Kenneth Stevens}

Department of Haematology,

University of Pretoria,

PO Box 2034,

Pretoria 0001 ,

South Africa

$$
\begin{aligned}
& \text { 1. Goodenough, O. \& Dawkins, T. Nature 371, 23-24 } \\
& \text { (1994). } \\
& \text { 2. Ernst, E., Saradeth, T. \& Resch, K. Nature 363, } 296 \\
& \text { (1993). } \\
& \text { 3. Dixon, B. Br. med. J. } 137 \text { (1993). } \\
& \text { 4. Seglen, P. J. intern. Med. } 229 \text { (2), 109-111 } \\
& \text { (1991). }
\end{aligned}
$$

\section{Visceral leishmaniasis and AIDS}

SIR - Visceral leishmaniasis (VL), a protozoan infection transmitted by sandflies, has a world-wide distribution that includes major endemic regions in the Mediterranean basin, East Africa, the Middle East, the Indian subcontinent and South America. More than 500,000 clinical cases occur annually (P. Desjeux, WHO; personal communication) and more than 200 million people are exposed to infection ${ }^{1}$. Skin tests and serology indicate that most individuals who receive an infective sandfly bite resist progression to clinical VL and that the ratio of asymptomatic to clinical cases ranges between 5 to 1 (Kenya), 10 to 1 (India) and 18 to 1 (Brazil) ${ }^{2}$. VL is primarily rural and suburban, but there is a trend towards urbanization (which has recently affected several state capitals in northeastern $\mathrm{Brazil}^{3}$ ), whereas HIV primarily becomes established in urban foci, from which it is disseminated into suburban and rural localities. Both VL and HIV predominate in males, although VL is often acquired at an early age as infant kala azar.

In the Mediterranean region, the recent shift in the age group prevalence of VL from infants to adults is not due to oscillations in VL incidence but is seen only where HIV is present and is in part associated with activation of disease in hitherto undetected asymptomatic carriers who are also infected with HIV. Thus, based on the small samples available from this area of low endemicity, most recent
VL cases have been in HIV patients, with several-fold increases recorded in the rate of VL associated with $\mathrm{HIV}^{4}$ (in southern Europe $50 \%$ of VL adult cases are now related to HIV infection), in parallel with the steadily rising prevalence of AIDS: 3-7 \% of HIV patients in this region develop VL and incidence has in some areas doubled in the past 2 years. Circumstantial evidence suggests that VL can also be transmitted among drug users by syringe passage.

VL/HIV co-infections present special problems. Indirect methods of diagnosis, such as serology, frequently fail; direct methods are reliable but have less value in treated and relapsing patients, are invasive and require skilled microscopy. Treatment of VL with conventional drugs, such as antimonials, amphotericin B, pentamidine and allopurinol, gives poor results with HIV patients; more than $40 \%$ relapse or have persistent chronic infections, demonstrating the importance of the immune response during chemotherapy. Studies are required to select better drug combinations for treating VL in the immunocompromised or for providing long-term prophylaxis, and to determine whether new DNA-based detection methods provide a solution to the diagnosis of persistent infections. Release of patients prone to relapsing back into VLendemic areas may sustain or generate new outbreaks.

Few VL/HIV co-infections have been reported from Central and South America, but the epidemiological features of both infections are similar to those of Europe. In the Americas, at least 1.5 million people are thought to be infected with VL, with 80,000 acquiring infection each year: both VL and HIV prevalences are rising and the rate of increase in HIV infection is much higher than in Europe. Further, HIV is spreading to suburban and rural areas, while VL is becoming urbanized. It seems inevitable, therefore, that VL/HIV co-infections will become commonplace in the Americas. A similar outcome may occur in India, where HIV infection is spreading, even though rural populations such as that of Bihar State, where VL has been epidemic, at present seem protected by infrequent interaction with HIV carriers in the cities 5 .

Overall, these comparisons indicate the need to be alert to the increasing sympatry between VL and HIV and the predictable rise in VL/HIV co-infections, and the need for a sense of urgency to the more effective management of outbreaks of VL.

\section{Miguel de Gorgolas}

Michael A. Miles

Department of Medical Parasitology,

London School of Hygiene

and Tropical Medicine,

Keppel Street,

London WC1E 7HT.

UK

$$
\begin{aligned}
& \text { 1. Ashford, R.W. Parasit. Today 8, 104-105 } \\
& \text { (1992). } \\
& \text { 2. Desjeux, P. Wid Hith Statist. Quart. 45, 267-275 } \\
& \text { (1992). } \\
& \text { 3. Brandao-Filho, S. \& Shaw, J. Parasit. Today 10, } \\
& \text { 329-330 (1994). } \\
& \text { 4. Alvar, J. Parasit. Today 10, 160-163 (1994). } \\
& \text { 5. Gupta A.K. \& Saran R. Ind. J. publ. Hith 37, 54-56 } \\
& \text { (1993). }
\end{aligned}
$$

\section{A line in the sea}

SIR - A line in the sea (J. A. Yoder et al. Nature 371, 689; 1994) has been previously described in 1960 by the french sailor Bernard Moitessier in his book Vagabond des Mers du Sud. In this account of his voyage in the South Atlantic between the Fernando Islands and the West Indies, about 150 miles southeast of Trinidad, he writes of: "a perfectly straight frothy line (in the sea), like a taut string, ... vanishing in the distance" (une ligne écumante bien droite, comme tracée au cordeau, .. . se perdant dans le lointain). $\mathrm{He}$ also observed a rapid change in sea colour (from green to blue), which he interpreted as a change in temperature.

\section{Daniel Schlaifer}

25 rue du Rhone,

31170 Tournefeuille,

France

François Siorat

$\angle P O$, lle Grande,

22560 Pleumeur Bodou,

France 